\title{
HOPE AS A PREDICTOR OF BULLYING
}

\section{Gökhan ATÍK*}

\begin{abstract}
The aim of this study was to investigate the role of hope, age, and gender in predicting bullying (victim, bully, bully/victim, and not involved). The sample consisted of 751 participants recruited from middle school students. The Revised Olweus Bully/Victim Questionnaire, Children's Hope Scale, and a brief demographic information form including participants' gender, age, and grade level were used for data collection. The data were analyzed using multinomial logistic regression analysis. The results revealed that higher hope scores decrease the likelihood that the subject is a victim or bully/victim. While being older increases the likelihood that the subject is a bully, being girl decreases the likelihood that the subject is a bully. The findings are discussed in the light of the literature with some suggestions for further studies.
\end{abstract}

Key Words: Bullying, hope, middle school students.

\footnotetext{
* Research Assistant, Ankara University, Faculty of Educational Sciences, e-mail: atik@education.ankara.edu.tr

*** Thanks to Yrd. Doç. Dr. Yeşim Çapa AYDIN for her contributions.
} 


\section{SUMMARY}

Problem Statement: In the recent years, bullying among students has become one of the most considerable concerns not only in western countries but also in Turkey. It influences students' well-being negatively and causes some problems, such as behavior problems, hyperactivity, conduct problems, peer problems, posttraumatic stress, depression and suicidal ideation, becoming violent, and decreased academic achievement, etc. Media and government reports and the studies conducted in Turkey indicate that bullying is a pervasive problem which needs to be addressed. Studies carried out in Turkey about prevalence rates of bullying give us warnings. Thus, in order to further the understanding of bullying in schools and to prevent bullying, investigating the effects of several factors and certain background variables deemed to be important.

Purpose of the Study: The purpose of the present study was to investigate the role of hope, age, and gender in predicting bullying (victim, bully, bully/victim, and not involved).

Method: The sample consisted of 751 participants recruited from middle school students. 350 of the participants were males (46.6\%) and 401 of the participants were females $(53.4 \%)$. Age of participants ranged from 11 to $15 \quad(M=13.11$, $S D=.929)$. The sample consisted of 275 sixth (36.6\%), 224 seventh (29.8\%), and 252 eighth $(33.6 \%)$ grade students. The instruments of this study were: The Revised Olweus Bully/Victim Questionnaire, Children's Hope Scale (Snyder et al., 1997), and a brief demographic information form including participants' gender, age, and grade level. In this study, the validity and a week stability of the Revised Olweus Bully/Victim Questionnaire were checked on a small group. The total scores of seven items related to being bullied were found to be positively and significantly correlated with the scores obtained from the Children Depression Inventory (CDI; Kovacks, 1985) $[n=29 ; r=.47, p<.05]$. Also, the total scores of seven items about bullying others were found to be positively and significantly correlated with the scores obtained from the Children's Social Behavior Scale (CSBS; Crick and Grotpeter, 1995) $[n=21 ; r=.43, p<.05]$. The stability of the 24 responses to the two global questions was checked with percentage agreement $(69.6 \%$ for observed percentage agreement, $71.8 \%$ for expected percentage agreement).

Results: Given that the predictor variables (hope, age, and gender) were combination of continuous and categorical, and outcome variable (bully, victim, bully/victim, not involved) was categorical with four levels, in order to determine a significant model that predicts bullying a multinomial logistic regression was used. The multinomial logistic regression analysis indicated that higher hope scores decreased the likelihood that the subject was a victim or bully/victim. While rising in age increased the likelihood that the subject was a bully, being girl decreased the likelihood that the subject was a bully.

Conclusion: Hope is a crucial concept in human life that is related to successful goal pursuits, well-being and self-esteem, preventive and protective in subsequent difficulties, and strengthening in various stress situations. The role of hopeful thinking in preventing problems and enhancing strengths of students should be taken into consideration while working with students not involved in bullying (primary prevention) and risk groups involved in bullying (secondary prevention). 


\section{ZORBALIĞI YORDAYICI BİR DEĞİŞKEN OLARAK UMUT}

\section{Gökhan ATÍK*}

ÖZ. Bu çalışmada, ilköğretim ikinci kademe öğrencileri arasındaki zorbalığı yordamada umut, yaş ve cinsiyetin rolünü incelemek amaçlanmıştır. Araştırmanın örneklemini, 751 ilköğretim ikinci kademe öğrencisi oluşturmaktadır. Veri toplama aracı olarak; Revize Edilmiş Olweus Zorba/Mağdur Anketi, Çocuklarda Umut Ölçeği ve katılımcıların cinsiyet, yaş ve sınıf düzeylerine ilişkin kişisel bilgi formu kullanılmıştır. Umudun, yaşın ve cinsiyetin zorbalığı yordamadaki rolünü incelemek için çoklu kategorik lojistik regresyon analizi kullanılmıştır. Elde edilen bulgulara göre; umut arttıkça ögrencilerin mağdur ve zorba/mağdur olma ihtimalleri düşmektedir. Ayrıca, yaştaki artış kişinin zorba olma ihtimalini artırırken, cinsiyetin kız olması kişinin zorba olma ihtimalini düşürmektedir. Elde edilen bulgular, literatür doğrultusunda tartışılmış ve sonraki çalışmalar için bazı önerilerde bulunulmuştur.

Anahtar Kelimeler: Zorbalık, umut, ilköğretim ikinci kademe öğrencileri.

\footnotetext{
* Araştırma Görevlisi, Ankara Üniversitesi, Eğitim Bilimleri Fakültesi, e-posta: atik@education.ankara.edu.tr

** Katkılarından dolayı Yrd. Doç. Dr. Yeşim Çapa AYDIN'a çok teşşekür ederim.
} 


\section{GİRIŞ}

Alan yazında birçok zorbalık tanımı yapılmış olmasına rağmen, herkesin tam olarak üzerinde anlaştığı bir tanım oluşturulamamıştır (Tattum, 1993). Bazı araştırmacılara göre zorbalık, saldırganlığın bir türü olarak düşünülürken (Orpinas ve Horne, 2006), bazı araştırmacılar tarafından da kişilerarası gücün saldırganlık ve şiddet yoluyla ifadesi olarak tanımlanmıştır (Craig ve Pepler, 2003). En yaygın olarak kullanılan tanımına göre zorbalık, bir öğrenciye bir veya birden fazla öğrenci tarafindan tekrarlanan bir biçimde olumsuz davranışların gösterilmesidir (Olweus, 1993). Zorbalığı şiddet ve saldırganlık gibi benzer kavramlardan ayıran özellikler; zorbalık davranışının kasıtlı bir niyetle yapılması, mağdur olan kişinin kendisini koruyamaması, bir güç dengesizliğinin olması ve bu davranışların tekrarlanan bir biçimde devam etmesidir (Rigby, 2001; akt. Rigby, 2004, s. 288).

Gelişmiş ülkelerde insan haklarına ilişkin bilincin artması ve özellikle medyanın rolü ile bu kavrama olan hassiyet artmıştır (Smith, 2000). Son yıllarda özellikle eğitim ortamlarında, artan derecede dikkat çeken zorbalık, olumsuz etkileri de gözönünde bulundurulduğunda, birçok ülke için kayg1 verici bir hal almıştır (Barrio, Martín, Montero, Fernández ve Gutiérrez, 2001; Finkelhor, Ormrod, Turner ve Hamby, 2005; Gini, 2004; Solberg ve Olweus, 2003; Wolke, Woods, Bloomfield ve Karstadt, 2000). Ülkemizde yapılan çalışmalar, benzer şekilde, bu konunun kaygı verici boyutuna dikkat çekmektedir (Atik, 2006; Kapçı, 2004; Kepenekçi ve Çınkır, 2006). Son zamanlarda basına yansıyan okullardaki şiddet olayları ile çocuklar ve gençlerde artan şiddet eğilimi ve okullarda meydana gelen olaylarının araştırılması amaciyla kurulan Meclis araştırması komisyonunun yayımladığ1 rapor (TBMM, 2007) bu konunun ciddiye alınması gerektiğini göstermektedir.

Zorbalığın eğitim ortamlarında giderek artan bir sorun olmasının yanı sıra, öğrenciler üzerinde yarattığ 1 olumsuz etkiler de ayrı bir tehdit unsuru olarak ortaya çıkmaktadır. Örneğin, Wilkins-Shurmer ve arkadaşları (2003), zorbalığa uğrayan bir ergenin anlamlı bir derecede psikososyal yaşam kalitesinin düştüğünü belirtmişlerdir. Depresyon ve intihar etme düşüncesi de mağdur olmanın yaygın bir sonucu olarak ortaya çıkmaktadır (Wal, Wit ve Hirasing, 2003). Ayrıca, zorbalığa dahil olanların zararlı madde kullanımı, hırsızlık, eşyalara zarar verme, anne-babaya ve okul kurallarına karşı gelme gibi davranış sorunları yaşadıkları bulunmuştur (Haynie, Nansel, Eitel, Crump, Saylor, Yu ve ark., 2001). Bununla birlikte, zorbalığa dahil olmuş çocukların psikiyatrik sorun yaşama ihtimallerinin de diğer dahil olmayan öğrencilere göre daha yüksek olduğu da araştırma bulgularında 
belirtilmiştir (Kumpulainen, Rasanen ve Puura, 2001). Mynard, Joseph ve Alexandera (2000) mağdur olan öğrencilerin yüksek düzeyde post-travmatik stres bozukluğu yaşadıklarına işaret etmiştir. Bir başka bulgu olarak da, zorbalığa dahil olan öğrencilerin akademik başarıları ve performansları olumsuz bir şekilde etkilenmektedir (Pekel, 2004; Wilkins-Shurmer ve ark., 2003).

Araştırmanın yordayıcı değişkeni olan umut, bireyin psikolojik ve fiziksel iyi oluşunu yordamada pozitif bir role sahiptir (Snyder, Feldman, Shorey ve Rand, 2002). Snyder, Feldman, Taylor, Schroeder ve Adams (2000) umutlu düşüncenin sorunları önlemede ve dayanıklılığı arttırmadaki önemini vurgulamışlardır. Umudun, sorun ortaya çıkmadan önceki (temel önleme) ve sonraki aşamalarda (ikincil önleme) önleyicilik açısından önemli katkıları olabileceği belirtilmektedir. Snyder ve arkadaşları (2000) ayrıca, yüksek umut düzeyinin, kişilerin iyilik halini ve benlik algısını arttırdığını belirtmiştir. Bilişsel bir süreç olan umut kavramı, kişinin amaçlarına ulaşmada yöntemler geliştirebilmesi ve bunları uygulayabilmesi açısından bir araç olmaktadır. Kişi ihtiyaçlarını karşılarken daha önce kullandığı stratejileri tercih etmektedir. Umut ile zorbalık arasında bir bağlantı kurulduğunda, şiddet olayları bu tür olaylara maruz kalan çocukların umut düzeylerini olumsuz bir şekilde etkilemektedir (Hinton-Nelson, Roberts ve Snyder, 1996). Osofsky (1995) şiddet ortamında yetişen çocukların yaşamdan ve gelecekten beklentilerinin düşük olduğunu belirtmektedir. You, Furlong, Felix, Sharkey ve Tanigawa (2008) tarafindan yapilan bir çalışmada, okul ortamında mağdur olan öğrencilerin umut ve okula bağlanma düzeylerinin düşük seviyede olduğu bulunmuştur. Bir başka çalışmada (Oskin, 1997), küçük çocuklar için, mağdur olma ile umut arasında negatif bir ilişki bulunmuştur. Bu açıdan, zorbalığa maruz kalan çocukların maruz kalmayanlara göre daha düşük umut düzeylerine sahip olabileceği düşünülmektedir. Ayrıca, zorbalığa maruz kalan çocuklar, zorbalıkla başetmede çözüm yolları üretebilme ve gerçekleştirebilme anlamında da sorun yaşayabilirler.

Alan yazında, umut ile mağdur olma arasındaki ilişkiye yönelik kısıtlı bir çalışma alanının olmasına rağmen, zorba veya zorba/mağdur olma ile umut arasındaki ilişkiye yönelik herhangi bir çalışmaya rastlanmamıştır. Ayrıca, okullarda zorbalıkla ilişkili olabilecek değişkenlerin anlaşılması, geliştirilecek olan önleyici programlara ve psikolojik danışma hizmetlerine rehberlik etmesinin yanısıra, okullarda alınacak önlemlerin belirlenmesi açısından da önem taşımaktadır. Bu bağlamda, bu araştırma, ilköğretim ikinci kademe öğrencileri arasındaki zorbalık davranışını yordamada umudun rolünü belirlemeyi amaçlamaktadır. 


\section{YÖNTEM}

\section{Araştırma Grubu}

Araştırmada kolayda örnekleme (convenient sampling) yöntemi kullanılmıştır. 2005-2006 öğretim yılında gerçekleştirilen araştırmaya, Ankara'nın Altındağ ilçesine bağlı dört ilköğretim okuluna devam eden 751 ögrenci katılmıştır. Katılımcıların 401'ini (\%53.4) kız, 350'sini (\%46.6) erkek öğrenciler oluşturmaktadır. Yaşları 11 ile 15 arasında değişen ( $\bar{X}=13.11, S S=.929)$ katılımciların 275'i 6. sinıf (\%36.6), 224'ü 7. sinıf (\%29.8) ve 252'si 8. sinıf (\%33.6) öğrencisidir.

\section{Veri Toplama Araçları}

Araştırmada öğrencilerin cinsiyet, yaş ve sınıf bilgilerini içeren kişisel bilgi formu ile Revize Edilmiş Olweus Zorba/Mağdur Anketi (Dölek, 2002) ve Çocuklarda Umut Ölçeği (Atik ve Kemer, 2007) kullanılmıştır.

Revize Edilmiş Olweus Zorba/Mağdur Anketi (REOZMA). Özellikle okullarda öğrencilerin zorba ve mağdur olma deneyimlerini değerlendiren Revize Edilmiş Olweus Zorba/Mağdur Anketi (REOZMA) Olweus (1996; akt. Dölek, 2002) tarafindan geliştirilmiştir. Bu ölçme aracı 40 maddeden oluşmakta ve zorbalık davranışının türünü ve sıklığını, nerede meydana geldiğini, kimler tarafından yapıldığını, öğrencilerin zorbalık davranışını ailelerine ve öğretmenlerine ne kadar sıklıkla anlattıklarını ve eğer öğretmenler zorbalık davranışını engellemek için müdahale ederlerse bunun için ne yaptıklarını belirlemektedir. Ölçme aracının orjinal çalışmasında, iç tutarlılığını test etmek için 5000'den fazla öğrenci üzerinde çalışılmıştır. Bu çalışmalarda; "mağdur olma" ve "başkalarına zorbalık yapma" ile ilgili maddelere ait Cronbach alfa katsayısı olarak .80 ve daha üzeri değerler elde edilmiştir. REOZMA'nın Türkçe'ye çevirisi Dölek (2002) tarafından yapılmış olup, bu çalışmada herhangi bir geçerlik ve güvenirlik çalışmasına rastlanmamıştır. Türkçe çevirinin kullanıldığ 1 başka bir çalışmada (Atik, 2006), "mağdur olma" ve "zorbalık yapma" ya ilişkin iç tutarlılık katsayısı sirasiyla .71 ve .75 olarak bulunmuştur.

Bu çalışmada, REOZMA'nın geçerliği ve tekrar ölçümleri arasındaki güvenirliği, ilköğretim ikinci kademe öğrencilerinden oluşan küçük bir grup üzerinde test edilmiştir. Buna göre; REOZMA'daki mağdur olma türlerine ilişkin maddeler ile Çocuk Depresyon Ölçeği'nden (Kovacks, 1985; Öy, 1991) elde edilen puanlar arasında anlamlı bir ilişki bulunmuştur $(n=29$; $r=.47, p<.05$ ). Ayrıca, zorbalık davranışı türlerine ilişkin maddeler ile Çocuk Sosyal Davranış Ölçeği'nden (Crick ve Grotpeter, 1995; Kapçı ve Kurnaz, 2008) elde puanlar arasında anlamlı bir ilişki bulunmuştur $(n=21 ; r=.43$, $p<.05)$. Bir hafta arayla yapılan iki ölçüm arasındaki uyuşmanın güvenirliği 
"yüzdelik uyuşma" ile test edilmiştir (Hunt, 1986). Çalışma yapılan grupta $(n=24)$, sadece "mağdur olan" ve bu tür olaylara "dahil olmayan" öğrencilere rastlandığı için, sadece bu gruplara ilişkin yüzdelik uyuşma test edilmiş ve gözlenen yüzdelik uyuşma $\% 69.6$ bulunurken, beklenilen yüzdelik uyuşması ise $\% 71.8$ bulunmuştur.

Öğrencileri "zorba, mağdur, zorba/mağdur ve dahil olmayan" şeklinde gruplandırmak için Solberg ve Olweus (2003) tarafından önerilen, biri mağdur grubu, diğeri ise zorba grubu belirlemeye yönelik olan iki soru kullanılmıștır. Bu sorular şöyledir: "Bu dönem okulda ne kadar sıklıkla zorbaca davranışa uğradın?" ve "Okulda diğer öğrencilere karşı ne kadar sık zorbaca davranışlarda bulundun veya zorbaca davranan bir grupta yer aldın?" Bu sorular; "bu dönem okulda zorbaca davranışa uğramadım ya da diğer öğrencilere zorbaca davranışlarda bulunmadım", "sadece bir veya iki kere oldu", "arada sırada", "haftada bir" ve "haftada birkaç kez" olmak üzere birden beşe kadar derecelenmektedir. Bu derelendirmede "arada sırada" ve üstünü işaretleyen öğrenciler, ilk soru için "mağdur", ikinci soru için "zorba" olarak gruplanmıştır. Her iki soruda da "arada sırada" ve üstünü işaretleyenler "zorba/mağdur", bu derecelendirmenin altını işaretleyenler ise "dahil olmayan" grup olarak sınıflandırılmıştır.

Çocuklarda Umut Ölçeği (ÇÜ̈). Snyder, Hoza, Pelham, Rapoff, Ware, Danovsky ve arkadaşları (1997) tarafindan geliştirilen Çocuklarda Umut Ölçeği (ÇUÖ), Atik ve Kemer (2007) tarafindan Türkçe'ye çevrilerek, geçerlik ve güvenirlik çalışmaları yapılmıştır. Çocukların sürekli umut düzeylerini belirlemek için kullanılan bu ölçek, toplamda 6 maddeden oluşmakta ve likert tipi derecelemeye uygun olarak; "Hiçbir Zaman=1, Nadiren=2, Bazen=3, S1k sık=4, Çoğu Zaman=5 ve Her Zaman=6" şeklinde derecelenmektedir. Ölçeğin puanlanması herbir maddeden alınan puanın toplanmasıyla yapılırken, ölçekten elde edilebilecek en yüksek puan 36, en düşük puan 6'dır. Ölçek "amaca ulaşma yolları" (pathways) ve "amaca güdülenme" (agency) olmak üzere iki boyuttan oluşmaktadır. Ölçekteki tek maddeler amaca güdülenme boyutunu, çift maddelerse amaca ulaşma yolları boyutunu oluşturmaktadır. Snyder ve arkadaşları (1997) umudun bu iki alt boyutun toplamından oluştuğu ve ayrı ayrı ele alınmaması gerektiğini belirtmektedir. Bunun için orijinal ölçek çalışmasında tüm ölçek için Cronbach alfa güvenirlik katsayısı hesaplanmış ve farklı örneklemlerde .72 ile .86 arasında değişen katsayılar elde edilmiştir. Ölçek için test-tekrar-test korelasyon katsayıs1 pozitif ve anlamlı bulunmuştur $(n=359 ; r=.71, p<.001)$ (Snyder ve ark., 1997). Bu çalışmadaki veri setinden yola çıkılarak yapılan ölçek uyarlamasında, iç-tutarlık güvenirlik Cronbach alfa katsayısı tüm ölçek için .74 bulunurken, test-tekrar-test güvenirlik korelasyon katsayısı pozitif ve 
istatistiksel olarak anlamlı bulunmuştur $(n=191 ; r=.57, p<.01)$ (Atik ve Kemer, 2007). Uyarlama çalışmasında yapı geçerliğine ilişkin bulgular, orijinal çalışmadaki iki faktörlü yapıyı desteklerken; iki faktörlü yapı varyansın yaklaşık \%58'ini açıklamıştır. Ayrıca ölçeğin uyum geçerliğine (convergent validity) ilişkin kanıtlar, ÇUÖ puanlarının benlik saygısı puanları ve akademik başarı ile olumlu ve anlamlı düzeyde ilişkili olduğunu göstermektedir. Artımsal geçerliğe (incremental validity) ilişkin kanıtlar, ÇUÖ puanlarının akademik başarıyı, çocukların benlik saygısından kaynaklanan puanların ötesinde yordadığı görülmüştür. Bu çalışmada, katılımcıların umut puanları, toplam puan üzerinden değerlendirilerek analize sokulmuştur.

\section{İşlem}

Milli Eğitim Bakanlığı'ndan yazılı izin alındıktan sonra, Ankara'nın Altındağ ilçesinde bulunan dört ilköğretim okulunun müdürlerine, araştırmanın amacının anlatılması ve uygulama onayının alınması için ziyaretler yapılmıştır. Okul müdürlerinin onayı alındıktan sonra, psikolojik danışma ve rehberlik servislerinin yardımıyla gönüllük esas alınarak kişisel bilgi formu ve iki ölçekten (REOZMA ve ÇUÖ) oluşan uygulama seti toplam 751 ilköğretim ikinci kademe öğrencisine verilmiştir. Uygulama 2005-2006 Eğitim Öğretim yılı Bahar döneminde araştırmacı tarafından sınıflarda gerçekleştirilmiştir. Araştırmanın amacı ve ölçeklere ilişkin yönergeler uygulama esnasında belirtilmiştir. Uygulama ortalama 25 dakika sürmüştür.

\section{Verilerin Analizi}

Gruplandırmadan sonra, veri seti gözden geçirilerek analize uygun hale getirilmiştir. Bunun için öncelikle, veri setindeki eksik değerlerin oranı incelenmiş ve değişkenlerin tümünde $\% 5$ 'in üzerinde herhangi bir eksik maddeye rastlanmamışır (Little's MCAR testi: $\left.\chi^{2}=6.431, s d=10, p=.778\right)$. Daha sonrasında eksik değerler aritmetik ortalama değeriyle tamamlanmıştır (Tabachnick ve Fidell, 2001). Veri setini çoklu kategorik lojistik regresyon analizine hazır hale getirmek için tek ve çok değişkenli uç değerler (univariate-multivariate outliers) belirlenmiştir. Bunun için, bir gözlem tek değişkenli aykırı değer olarak tanımlanmış ve veri setinden çıkartılmıştır. Çok değişkenli aykırı değerler incelemesinde Mahalanobis uzaklık (Mahalanobis Distance) değerleri kullanılmış ve .001 anlamlılık düzeyinde aykırı gözleme rastlanmamıştır. $\mathrm{Bu}$ analizler sonucunda veri seti 750 olarak belirlenmiştir. 


\section{BULGULAR}

Araştırmanın sonuç değişkeni, yani zorbalık davranışı (mağdur, zorba zorba/mağdur ve dahil olmayan) dörtlü kategorik bir değişken olduğu için çoklu kategorik lojistik regresyon analizi yapılmıştır. Çalışmanın yordayıcı değişkenlerini de umut, yaş ve cinsiyet değişkenleri oluşturmaktadır. Çoklu kategorik lojistik regresyon analizinin yürütülebilmesi için beklenen frekansların yeterliği, logitlerdeki doğrusallık ve çoklu bağlantı (multicollinearity) sayıltıları test edilmiştir. Öncelikle, kategorik değișkenler (cinsiyet) için beklenen frekansların yeterliği çapraz tablolama analiz yöntemi ile incelenmiş ve sonuçlar Tablo 1'de sunulmuştur. Buna göre; 5'in altında herhangi bir beklenen hücre frekansına rastlanmamış ve varsayımların testine devam edilmiştir.

Tablo 1. Cinsiyete Göre Zorbalık Türlerinin Frekans Dağılımı

\begin{tabular}{cllrrr}
\hline \multirow{2}{*}{ Değişkenler } & & \multicolumn{3}{c}{ Cinsiyet } & \multirow{2}{*}{ Toplam } \\
\cline { 3 - 6 } & Zorba & Gözlenen & 8 & Erkek & \\
\cline { 3 - 6 } & & Beklenen & 19.2 & 28 & 36 \\
\cline { 2 - 5 } Sonuç & Mağdur & Gözlenen & 81 & 62 & 36 \\
\cline { 2 - 6 } Değişken & Beklenen & $7 ., 3$ & 66.7 & 143 \\
\cline { 2 - 5 } & Zorba/Mağdur & Gözlenen & 10 & 16 & 26 \\
\cline { 2 - 6 } & & Beklenen & 13.9 & 12.1 & 26 \\
\cline { 2 - 6 } & Dahil Olmayan & Gözlenen & 301 & 244 & 545 \\
& & Beklenen & 290.7 & 254.3 & 545 \\
\hline \multirow{2}{*}{ Toplam } & Gözlenen & 400 & 350 & 750 \\
& Beklenen & 400 & 350 & 750 \\
\hline
\end{tabular}

Daha sonrasında Box-Tidwell yaklaşımı (Tabachnick ve Fidell, 2001) kullanılarak doğrusallık sayıltısı .05 anlamlılık düzeyinde incelenmiş ve sayıltının ihlal edilmediği görülmüştür. Son olarak; çoklu bağlantı (bkz. Tablo 2) sayıltısını test etmek için temel etkilerin yer aldığ1 modeldeki standart hata değerlerine bakılmıştır. Bu değerlerin 2'den küçük olduğu görülmüş ve değişkenler arasında çoklu bağlantının bulunmadığına karar verilmiştir. Böylelikle verilerin sayıltıları karşıladıkları gözlemlendikten sonra, çoklu kategorik lojistik regresyon analizi yapılmıştır.

Analiz sürecinin ilk aşamasında, sadece sabitten oluşan başlangıç modeli ile üç yordayıcı değişkenin yer aldığı tüm model karşılaştırılmış ve yordayıcıların bir set olarak sonuç değişkenin kategorileri arasında güvenilir şekilde ayırım yaptıkları görülmüştür $\left(\chi^{2}=44.220, s d=9, p<.001\right)$. Ancak, modelin öğrenci niteliklerini açıklama gücü düşük düzeyde bulunmuştur (McFadden $\rho^{2}=.036$, Nagelkerke $R^{2}=.071$ ). Modelin uygunluğunu değerlendirmek için oransal şans yoluyla açıklama oranı \%71.3 olarak hesaplanmıştır. Model tarafindan toplam açiklama oranı \%72.7 olup, bu oran şans yoluyla açıklama oranının üstünde kalmaktadır. Bu bulgulardan 


\section{TARTIŞMA ve SONUÇ}

Çoklu kategorik lojistik regresyon analizi sonuçlarına göre, yüksek umut puanları öğrencilerinin mağdur olma ve zorba/mağdur olma ihtimallerini düşürmektedir. Bir diğer deyişle, mağdur ve zorba/mağdur öğrencilerin umut düzeyleri dahil olmayan öğrencilere göre daha düşüktür. Alan yazını incelediğimizde, şiddete maruz kalan veya okul ortamında mağdur olan çocukların özellikle yaşama ilişkin umut düzeylerinin düşük olduğu görülmektedir (Hinton-Nelson, Roberts ve Snyder, 1996; Oskin, 1997; You ve ark., 2008). Ayrıca, Snyder ve arkadaşları (1997) erken çocukluk dönemindeki amaçlara yönelik engellerle başa çıkmanın umutlu düşünceyi geliştirdiğini ve çocukların karşılaşılan diğer zorluklardan bu umutlu düşünce sayesinde korunduklarını savunmuşlardır. $\mathrm{Bu}$ anlamda, umut bireyin psikolojik sağlamlığını arttırmada ve olumsuz durumlarda bireyi korumada önemli bir role sahiptir. Bunun dışında, umut düzeyi yüksek bireyler istedikleri amaca ulaşmak için birçok yol bulabileceklerine inanırlar (Snyder ve ark., 1991). Bu inanç sisteminin birey üzerinde önemli bir etkisi vardır. Özellikle engellerle karşılaşıldığında, sistemin etkisi bireyin yaklaşımını belirlemede dikkat çekici bir rol oynar (Snyder, Ilardi, Cheavens, Michael, Yamhure ve Sympson, 2000). Bu açıdan bakıldığında, yüksek umut düzeyi bireyin sorunla başetme ya da problem çözme becerisini geliştirmesine de katkıda bulunmakta ve bu beceriler sayesinde birey zorbalık, şiddet gibi olumsuz durumlarla başedebilmektedir.

Cinsiyet ve yaşın zorbalık davranışını yordamadaki rolü incelendiğinde, erkeklerin ve daha büyük öğrencilerin zorba olma ihtimallerinin yüksek olduğu görülmektedir. Alan yazındaki diğer araştırma bulgularına bakıldığında, bu bulguların tutarlılık gösterdiği görülmektedir. Birçok araştırma bulgusunda zorbalığın ve mağdur olmanın erkekler arasında daha yaygın olduğu görülmektedir (Atlas ve Pepler, 1998; Bosworth, Espelage ve Simon, 1999; Haynie ve ark., 2001; Natvig, Albrektsen ve Qvarnstrøm, 2001; Karatzias, Power ve Swanson, 2002; Kristensen ve Smith, 2003; Pekel, 2004). Bu durumun olası bir açıklaması sosyalleşme süreci olabilir (Orpinas ve Horne, 2006). Yani, erkekler tarafindan gösterilen şiddet içerikli davranışlar toplum tarafından daha hoşgörülü karşılanabilmektedir. Yaşın artmasıyla birlikte kişinin zorba olması ihtimalinin artması da benzer şekilde araştırma bulgularıyla tutarlıl1k göstermektedir (Kristensen ve Smith, 2003; Olweus, 1993). Bu çalışmalarda, küçük çocukların daha çok zorbalığa maruz kaldıkları belirtilmiştir.

Sonuç olarak, bu araştırma bulguları Türkiye'deki zorbalık kavramının anlaşılması ve zorbalıkla başetmede geliştirilecek önleyici çalışmaların planlanmasında okul psikolojik danışmanları, aileler, ögretmenler, okul 
idarecileri ve politika belirleyiciler için birtakım ipuçları sağlayabilir. Ayrıca, umudun çocuklukta kazanılan bir özellik olduğu gözönüne alınırsa çocukluk döneminde yaşamın farklı alanlarına ilişkin umutlu düşüncenin geliştirilmesi ve sürdürülmesi önem kazanmaktadır. Snyder ve arkadaşları (2002) umudun çocuğun yaşamındaki etkisinin psikolojik danışmanlar tarafından anlaşılmasının önemini vurgulamışlardır. Bu açıdan, okullarda umutlu düşüncenin arttırılması hem temel önleme hem de ikincil önleme açısından önemli katkılar sağlayacaktır. Ayrıca, okullarda zorbalıkla mücadele ederken çok boyutlu ve birçok önleyici yöntemi içeren eylem planlarının düşünülmesi gerekmektedir. $\mathrm{Bu}$ anlamda önleyici çalışmaların daha etkili yürütülebilmesi için zorbalıkla ilişkili olabilecek riskli ve koruyucu faktörlerin tanımlanması gerekmektedir. Önleyici ve azaltıcı çalışmaların sadece belli bir gruba sunulmayıp, tüm sosyal içeriği ya da ortamı içine alabilecek şekilde sunulması gerekmektedir.

$\mathrm{Bu}$ çalışmanın birtakım sınırlılıkları bulunmaktadır. Öncelikle, bu çalışma devlete bağlı ilköğretim okulları kapsamında yapılmıştır ve bulguların genellenebilirliği bu çalışmaya katılan öğrenciler ve okullar kapsamında sınırlıdır. Ayrıca, bu çalışmanın bulguları ölçme araçlarından elde edilen verilerle sınırlı olup, daha sonraki çalışmalarda öğrencilerin zorba, mağdur, zorba/mağdur ve dahil olmayan şeklinde sınıflandırırken çeşitli değerlendirme yöntemlerinin (akran ve öğretmen değerlendirmeleri, gözlem, vb.) kullanılmasının, bu sinıflandırmanın daha sağlıklı olması açısından faydalı olacağ 1 düşünülmektedir. Bununla birlikte, bu çalışma kapsamında kullanılan Revize Edilmiş Olweus Zorba/Mağdur Anketi'nin sonraki çalışmalarda daha kapsamlı geçerlik ve güvenirlik çalışmasının yapılması da gerekmektedir.

Son olarak, bu çalışmada zorbalık sonuç değişkeni, umut ise yordayıcı bir değişken olarak ele alınmıştır. Ancak, umut zorbalık veya şiddet gibi durumlara karşı koruyucu bir faktör olabileceği gibi, aynı zamanda umut düzeyi yüksek bireylerin bu tür olaylara maruz kaldıklarında umut düzeylerinin düşmesi de söz konusu olabilir. Bu açıdan, zorbalık veya mağdur olma sonraki çalışmalarda yordayıcı bir değişken olarak değerlendirilebilir. Ayrıca, sonraki çalışmalarda, hem zorbalığı hem de umudu etkileyebilecek aracı faktörler de ele alınabilir. 


\section{KAYNAKLAR}

Atik, G. ve Kemer, G. (17-19 Ekim, 2007). Çocuklarda Umut Ölçeği'nin geçerlik ve güvenirlik çalışmaları. IX. Ulusal Psikolojik Danışma ve Rehberlik Kongresi, İzmir.

Atik, G. (2006). The role of locus of control, self-esteem, parenting style, loneliness, and academic achievement in predicting bullying among middle school students. Yayımlanmamış Yüksek Lisans Tezi. Orta Doğu Teknik Üniversitesi, Ankara.

Atlas, R. S., \& Pepler, D. J. (1998). Observations of bullying in the classroom. The Journal of Educational Research, 92(2), 86-99.

Barrio, C. D., Martín, E. Montero, I., Fernández, I., \& Gutiérrez, H. (2001). Bullying in Spanish secondary schools: A study on a national scale for the Ombudsman's Report on school violence. The International Journal of Children's Rights, 9, 241-257.

Bosworth, K., Espelage, D. L., \& Simon, T. R. (1999). Factors associated with bullying behavior in middle school students. Journal of Early Adolescence, 19(3), 341-362.

Craig, W. M., \& Pepler, D. J. (2003). Identifying and targeting risk for involvement in bullying and victimization. The Canadian Journal of Psychiatry-In Review, 48(9), 577-582.

Crick, N. R., \& Grotpeter, J. K. (1995). Relational aggression, gender, and social psychological adjustment. Child Development, 66, 710-722.

Dölek, N. (2002). Illk ve orta öğretim okullarındaki öğrenciler arasında zorbaca davranışların incelenmesi ve "Zorbalığg önleme tutumu geliştirilmesi programı"nın etkisinin araştırılması. Yayımlanmamış Doktora Tezi. Marmara Universitesi, İstanbul.

Finkelhor, D., Ormrod, R., Turner, H., \& Hamby, S. L. (2005). The victimization of children and youth: A comprehensive, national survey. Child Maltreatment, 10(1), 5-25.

Gini, G. (2004). Bullying in Italian schools. School Psychology International, 25(1), 106-116.

Haynie, D. L., Nansel, T., Eitel, P., Crump, A. D., Saylor, K., Yu, K., \& et al. (2001). Bullies, victims, and bully/victims: Distinct groups of at risk youth. Journal of Early Adolescence, 21(1), 29-49.

Hinton-Nelson, M. D., Roberts, M. C., \& Snyder, C. R. (1996). Early adolescents exposed to violence: Hope and vulnerability to victimization. American Journal of Orthopsychiatry, 66(3), 346-353.

Hunt, R. J. (1986). Percent agreement, Pearson's correlation, and kappa as measure of inter-examiner reliability. Journal of Dental Research, 65(2), 128-130. 
Kapçı, E. G. ve Kurnaz, A. (2008). Çocuk Sosyal Davranış Ölçeği'nin geçerlik ve güvenirlik çalışması. Yayımlanmamış araştırma. Ankara Üniversitesi, Eğitim Bilimleri Fakültesi.

Kapçı, E. G. (2004). İlköğretim öğrencilerinin zorbalığa maruz kalma türünün ve sıklığının depresyon, kaygı, ve benlik saygısıyla ilişkisi. Ankara Üniversitesi Ë̆itim Bilimleri Fakültesi Dergisi, 37(1), 1-13.

Karatzias, A. Power, K. G., \& Swanson, V. (2002). Bullying and victimisation in Scottish secondary schools: Same or separate entities? Aggressive Behavior, 28, 45-61.

Kepenekçi, Y. K., \& Çınkır, Ş. (2006). Bullying among Turkish high school students. Child Abuse and Neglect, 30, 193-204.

Kovacks, M. (1985). The Children's Depression Inventory. Psychopharmacology Bulletin, 21, 995-998.

Kristensen, S. M., \& Smith, P. K. (2003). The use of coping strategies by Danish children classed as bullies, victims, bully/victims, and not involved, in response to different (hypothetical) types of bullying. Scandinavian Journal of Psychology, 44(5), 479-488.

Kumpulainen, K., Räsänen, E., \& Puura, K. (2001). Psychiatric disorders and the use of mental health services among children involved in bullying. Aggressive Behavior, 27, 102-110.

Mynard, H., Joseph, S., \& Alexandera, J. (2000). Peer-victimisation and posttraumatic stress in adolescents. Personality and Individual Differences, 29, 815-821.

Natvig, G. K., Albrektsen, G., \& Qvarnstrøm, U. (2001). Psychosomatic symptoms among victims of school bullying. Journal of Health Psychology, 6(4), 365-377.

Olweus, D. (1993). Bullying at school: What we know and what we can do? Oxford, Blackwell.

Orpinas, P., \& Horne, A. M. (2006). Bullying prevention: Creating a positive school climate and developing social competence. Washington, DC: American Psychological Association.

Oskin, D. L. (1997). Realistic control perceptions, age, and gender as moderators of the relationship between victimization and hope in children. Poster session presented at the biennial meeting of the Society for Research in Child Development, Washington, D.C. ERIC Document Reproduction No. ED407095.

Osofsky, J. (1995). The effects of exposure to violence on young children. American Psychologist, 50, 782-788. 
Öy, B. (1991). Çocuklar için depresyon ölçeği: Geçerlik ve güvenirlik çalışmas1. Türk Psikiyatri Dergisi, 2, 132-136.

Pekel, N. (2004). Akran zorbaliğ grupları arasında sosyometrik başarı durumlarının incelenmesi. Yayımlanmamış Yüksek Lisans Tezi. Hacettepe Üniversitesi, Ankara.

Rigby, K. (2004). Addressing bullying in schools: Theoretical perspectives and their implications. School Psychology International, 25(3), 287300.

Smith, P. K. (2000). Bullying and harassment in schools and the rights of children. Children and Society, 14, 294-303.

Snyder, C. R., Feldman, B. D., Shorey, H. S., \& Rand, K. L. (2002). Hopeful choices: A school counselor's guide to hope theory. Professional School Counseling, 5(5), 298-307.

Snyder, C. R., Feldman, D. B., Taylor, J. D., Schroeder, L. L., \& Adams, V. III. (2000). The roles of hopeful thinking in preventing problems and enhancing strengths. Applied and Preventive Psychology, 15, 262-295.

Snyder, C. R., Harris, C., Anderson, J. R., Holleran, S. A., Irving, L. M., Sigmon, S. T., \& et al. (1991). The will and the ways: Development and validation of an individual-differences measure of hope. Journal of Personality and Social Psychology, 60, 570-585.

Snyder, C. R., Hoza, B., Pelham, W. E., Rapoff, M. Ware, L., Danovsky, M., $\&$ et al. (1997). The development and validation of the Children's Hope Scale. Journal of Pediatric Psychology, 22(3), 399-421.

Snyder, C. R., Ilardi, S. S., Cheavens, J., Michael, S. T., Yamhure, L., \& Sympson, S. (2000). The role of hope in cognitive-behavior therapies. Cognitive Therapy and Research, 24(6), 747-762.

Solberg, M. E., \& Olweus, D. (2003). Prevalence estimation of school bullying with the Olweus Bully/Victim Questionnaire. Aggressive Behavior, 29, 239-268.

Tabachnick, B. G., \& Fidell, L. S. (2001). Using Multivariate Statistics. $4^{\text {th }}$ Ed. Needham Heights, MA: Allyn ve Bacon.

Tattum, D. (1993). Understanding and Managing Bullying. Oxford: Heinemann School Management.

TBMM (2007). "Çocuklarda ve Gençlerde Artan Şiddet Eğilimi ile Okullarda Meydana Gelen Olayların Araştırılarak Alınması Gereken Önlemlerin Belirlenmesi Amacıyla Kurulan Meclis Araştırması Komisyonunun Raporu" [Online]: http://www.tbmm.gov.tr/develop/owa/arastirma_onergesi_gd.onerge_bi lgileri?kanunlar_sira_no $=491$ adresinden 22 Mart 2008 tarihinde indirilmiştir. 
Wal, M. F., Wit, C. A. M., \& Hirasing, R. A. (2003). Psychosocial health among young victims and offenders of direct and indirect bullying. Pediatrics,111(6), 1312-1317.

Wilkins-Shurmer, A., O'Callaghan, M. J., Najman, J. M., Bor, W., Williams, G. M., \& Anderson, M. J. (2003). Association of bullying with adolescent healthrelated quality of life. J. Paediatr. Child Health, 39, 436-441.

Wolke, D., Woods, S., Bloomfield, L., \& Karstadt, L. (2000). The association between direct and relational bullying and behaviour problems among primary school children. J. Child Psychol. Psychiat., 41(8), 989-1002.

You, S., Furlong, M. J., Felix, E., Sharkey, J. D., \& Tanigawa, D. (2008). Relations among school connectedness, hope, life satisfaction, and bully victimization. Psychology in Schools, 45(5), 446-460. 